\title{
INVISIBLE MEDIATIONS
}

\section{THE ROLE OF ADAPTATION AND DUBBING PROFESSIONALS IN SHAPING US TV FOR ITALIAN AUDIENCES}

\author{
Luca Barra \\ Dipartimento di Scienza della Comunicazione e dello Spettacolo \\ Cattolica del Sacro Cuore \\ Via S. Agnese 2 \\ 20123 Milan \\ Italy \\ luca.barra@unicatt.it
}

\begin{abstract}
With the increasing global circulation of media products, professionals devoted to the process of audiovisual translation and 'national mediation' for foreign ready-made programmes have gained a central role in contemporary TV. Presenting the results of an ethnographical study, this essay explores the 'invisible art' of TV adaptation and dubbing, explaining its procedures, traditions and challenges. Adaptation has to consider both the technical necessities of the audio-visual and cross-cultural aspects of translation, while dubbing involves extremely intricate production routines, professionals with different skills, written and unwritten rules, a range of different workplaces, economic investments and traditions. The result is a new text, modified following contrasting linguistic, cultural and professional goals.
\end{abstract}

Keywords: Adaptation, Dubbing, Global Circulation, National Mediation, Media Industries, Italian Television

\section{Global Circulation, National Reappropration}

The international distribution of TV shows has created a 'global television marketplace, ${ }^{11}$ where audiences of different nations can become familiar with the same characters, narratives and formats. Meanwhile, however, these global products often acquire different values, and sometimes even different forms, according to the varied contexts, cultures and nations that they are inserted into. ${ }^{2}$

In fact, as the same products spread all over the world, the importance of 'national mediation' - the complex set of practices used by broadcasters to acquire a foreign product and then show it to the national public - grows, to bridge the gap to local cultural and media objects originally intended for other audiences with different languages and backgrounds. The forms of this mediation play a crucial role and, often unnoticed by viewers, impact deeply on foreign texts, creating national editions that differ in many ways from the original TV shows on which they were based. Readymade products - such as series, sitcoms and factual programming - are adapted and dubbed before being aired on pay and free channels, and this 'invisible art,' as it is sometimes called, profoundly re-shapes the original audio and video, thus affecting the value, the meaning and the success of many titles. 
When Italian viewers watch a US TV series or sitcom, the product is, often unbeknown to them, different from the one its original audience enjoyed. Many jokes, references and plays on words are reconstructed to better fit another culture, society and media system. And even the choice of single words, the structure of some phrases, or the actors' intonations may differ at least slightly from the intentions of the original authors and producers from abroad.

This mediation seeks to translate and adapt the original product for a better fit to the target culture. The process is guided not only by linguistic and cultural aims but also by economic goals and professional habits. As highlighted by many recent studies on 'production culture' in media industries, ${ }^{3}$ the complex mixture of working practices, professionals' established ideas and trade know-how defines a field - or, to use a loaded term, a professional ideology: a coherent group of assumptions and undisputed routines - that results in modifications and different development trajectories. Consequently, when working on the original TV series, the adaptation and dubbing professionals are often looking both for a good rendering of foreign dialogues and for ways to make their job easier. How does this complex mediation process work? How many professionals are involved in the localization and adaptation of foreign TV products? What are their roles and habits? In what ways does the nature of this 'invisible mediation' affect the Italianized result, and what approaches are followed?

This essay seeks to answer these questions, presenting the results of an extended ethnographical study that examined how the Italian editions of The Simpsons (XVIII season, dubbed in 2007) and How I Met Your Mother (V season, dubbed in 2010) were produced, through in-depth interviews with many professionals involved, industry data gathering and participant observation during translation and adaptation processes. ${ }^{4}$ The two sitcoms, firstly aired on the same commercial network (Italia 1) and then repeated by several digital channels (Fox Italia the former, Premium Joi and Italia 2 the latter), were still on air with incoming new seasons, and constitute perfect examples of multilayered texts, with a complex batch of topics, references and puns that have to be shifted for a different national audience and then can provide a dense battleground for contrasting ideas, labour habits and procedures.

While the majority of the research on these themes is made from a mainly linguistic or cultural point of view, ${ }^{5}$ this essay aims to detail and generalize the various steps in the process of adapting and dubbing foreign TV series for Italian audiences. Thus, it adopts a perspective focused on media industries and their production cultures - able to deepen an often oversimplified idea of dubbing and underline the important role of professionals -, and concentrates as well on the specificities in the mediation of television products. Italy is a particularly interesting case among other European dubbing countries (like France, Germany, or Spain), not so much for the widespread and enduring perception that the 'Italian school' of dubbing is one of the best and most accurate in the world ${ }^{6}$ as for its long tradition, which has helped to establish fixed routines, shared best practices, and clearly defined professional roles: even if a large part of these processes are standard international routines, it is into the Italian media landscape that they reach a full extent, and a certain level of self-reflexivity. The 'complex machine' that translates, adapts and prepares the dubbing of every imported TV show can be best analyzed in this context.

\footnotetext{
3 John T. Caldwell, Production Culture. Industrial Reflexivity and Critical Practice in Film and Television, Duke, 2008; Mark Deuze, Media Work, Polity, 2007; Vicky Mayer, Miranda J. Banks, John T. Caldwell, eds., Production Studies. Cultural Studies of Media Industries, Routledge, 2009; Timothy Havens, Amanda Lotz, Understanding Media Industries, Oxford University Press, 2012.

${ }^{4}$ Luca Barra, 'The Mediation is the Message. Italian Regionalization of US TV Series as Co-Creational Work', International Journal of Cultural Studies, 12(5), 2009, 509-525; Luca Barra, Risate in scatola. Storia, mediazioni e percorsi distributivi della situation comedy americana in Italia [Canned laughter. History, mediations and distribution approaches of American situation comedy in Italy], Vita e Pensiero, 2012.

${ }^{5}$ See, for instance: Delia Chiaro, Christiane Heiss, Chiara Bucaria, eds., Between Text and Image. Updating Research in Screen Translation, John Benjamins, 2008; Jorge Diaz-Cintas, Gunilla M. Anderman, eds., Audiovisual Translation. Language Transfer on Screen, Palgrave MacMillan, 2009; Jan Pedersen, Subtitling Norms for Television, John Benjamins, 2011; Frederic Chaume Varela, Audiovisual Translation. Dubbing, St. Jerome, 2012; or Christina Adamou, Simone Knox, 'Transforming Television Drama through Dubbing and Subtitling. Sex and the Cities', Critical Studies in Television, 6(1), 2011, 1-21.

${ }^{6}$ Mario Paolinelli, Elena Di Fortunato, Tradurre per il doppiaggio [Translating for dubbing], Hoepli, 2005.
} 


\section{Translating, Adapting, Mediating}

The task of preparing the Italian edition of a foreign TV series is coordinated by the broadcaster that will air the product. It exercises ever-present editorial and technical control, which is achieved in practice through several specialist professional mediators working across the film and media industry.

The international distributor usually provides the networks with important starting materials: the videos of every episode, the original scripts with the English dialogue, and the international soundtrack containing music, noises and other sounds that are not to be changed. All this forms the basis for the first step towards the national edition: translation. During this phase, one or more specialist translators produce a first version of the Italian dialogue for each episode: sometimes, to speed up the process, each professional works on a single episode, or some parts of it, while others translate other episodes or parts of the same series.

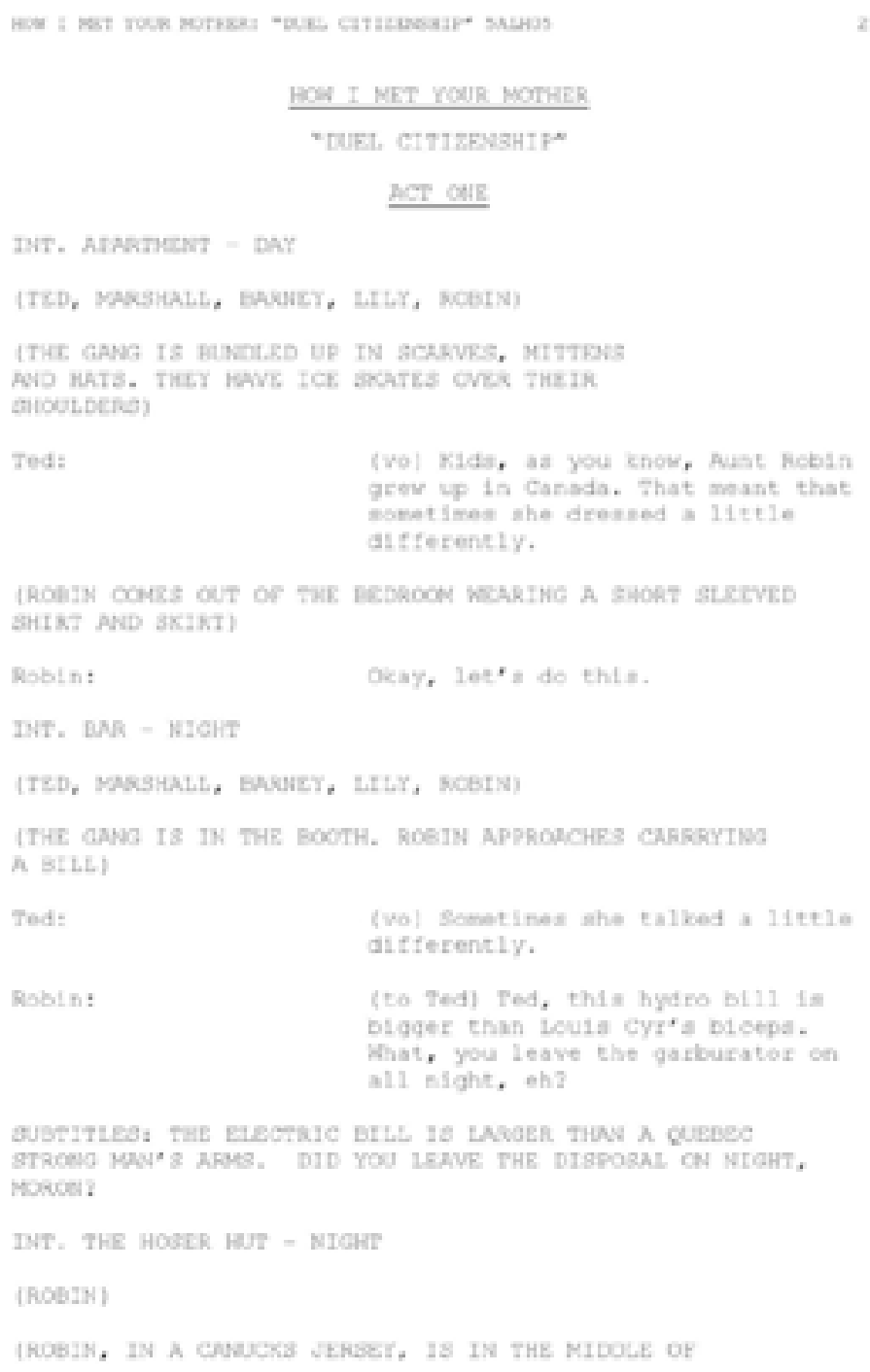

Fig. 1. The first page of the original script of How I Met Your Mother, 'Duel Citizenship', 5: 5 
Unlike in literary translation, this version of the dialogue is far from definitive, and (at least in some parts) is constantly negotiated and refined to facilitate the subsequent steps. After an initial viewing and a briefing about the series (frequently skipped for lack of time), the translators follow the original audio and video, read the English script and devise an Italian version that takes into account, at least partially, the timing of the dialogues. On one hand, the main goals at this stage are fidelity to the original script and accuracy in tone and meaning; on the other, the translation must always be a useful tool for the whole Italianization process - the linguistic and cultural mediation according to the Italian audiences' implied needs and habits. Therefore, through trial and error, the translation is shaped to be 'bold' and full of information: the document is marked with guidance on intonation, voices and emotions, e.g. '(vo)' for voice-over, '(ft)' for a short breath (fiato), '...' for a short pause, and ' $"$ ' for a longer one; ${ }^{7}$ every cultural, social or media reference is explained in detail, with clarifications and various translation proposals via dedicated notes ( $n d t)$; and jokes and slang are Italianized in several ways, thus offering the adaptor more than one acceptable solution.

I usually try to stay as close as possible to the original version, to provide the adaptors the fullest scope so that they can decide later. That's why the translations are full of notes and explanations, to give them all the information they need. ${ }^{8}$

Hence, the translation stage often becomes a standard, routine procedure, with fixed equivalences, the same points requiring attention, and limited 'creative' solutions. This first Italian version is a draft, a canovaccio, a work in progress on which the subsequent adaptation will be based.

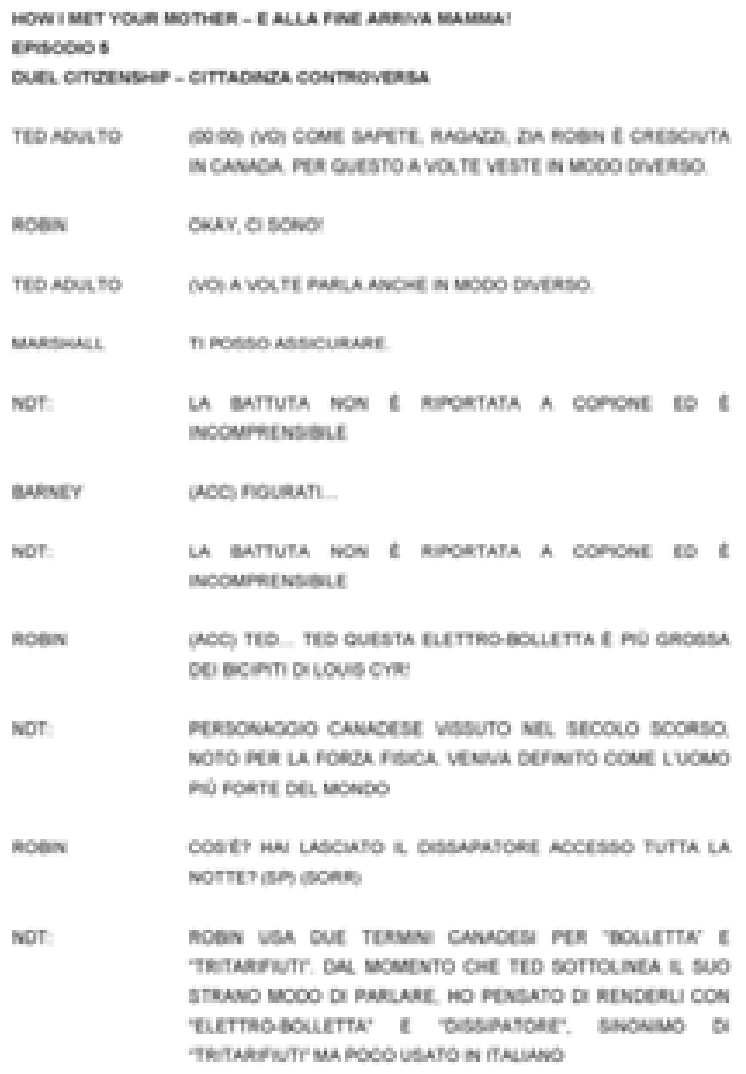

Fig. 2. The first page of the Italian translated version of How I Met Your Mother, 5: 5

7 Data collected in the participant observation during the translation of How I Met Your Mother, 2010.

${ }^{8}$ Antonella Radice, one of the translators for the Italian edition of How I Met Your Mother, interview, 2010. 
After a quick proofread, the translation is handed on to another professional, often a non-translator, who will carry out the adaptation and complete the Italian dialogues: the adaptor. At this stage, the translated script is revisited, and often completely rewritten, in order to address - as a much higher priority than fidelity to the original version - the technical necessities arising from the audiovisual and cultural aspects of its reception by an audience linguistically and socially different from its intended original one.

The adaptor/dialogist carefully watches every episode, tries out the translated text to see how it fits when read out with the video, and recreates the lines to suit the movements and timings on screen. With a well-trained eye and ear, they repeat and finely adjust each line until it is perfectly synchronized with the screen and 'naturally' meaningful for the viewer. As a result, the original foreign text becomes increasingly distant, as progressive adjustments, additions and deletions are made to its Italian counterpart.

\author{
HOWI MET YOUR MOTHER - E ALLA FINE ARRIVA MAMMA:


In more detail, the adaptation takes place on three different levels. The first is to round off the translator's work, as all the pauses and intonations are inserted into the draft to guide the recording of the lines during the dubbing, and the script is polished.

On a second level, adaptation transforms the dialogue to meet the different, and often contrasting, goals of synchronism and simplicity. The words in each phrase have to reflect the movements of the actors' mouths on screen and, more generally, the pauses and rhythms in their acting - although a lip sync, ${ }^{9}$ with a perfect match between (foreign) lips and (Italian) sounds, is difficult to obtain and is commonly sought only for the more prominent vowels, an expressive synchronism is always needed:

You have to pay attention to the rhythms; it is very important they are close to the original. If the actor's mouth moves at a certain speed, you have to follow that as much as possible, modifying the number of syllables and the words you have decided to use. The Italian rhythm must follow the internal rhythm of the video, with its changes and cuts, and of the pauses that must be maintained..$^{10}$

Meanwhile, this work on the length and construction of the dialogues must not interfere with the meaning of the scenes and phrases: another target in the adaptation process is to keep the characters and their way of speaking realistic and natural in the target language.

This leads to the third level of adaptation: the modification of content, wordplay and cultural references, and other semantic choices. Here, the adaptor polishes the dialogue, finds different synonyms, changes tone and register, fixes the jokes and the intertextual elements to make them better understood by the (implied) audience, according to his/her established ideas and usual adaptation practice. The main choice is between the two different strategies of foreignization, a source-oriented attempt to remain loyal to the original and bring the viewer partially into the foreign environment, and domestication, a target-oriented way to simplify the text and mould it to the target national culture. ${ }^{11}$ The dialogist uses an array of tools and strategies - e.g. reduction, generalization, equivalence and substitution - to refine the various elements: e.g. figures of speech, accents and other characteristic linguistic details; aspects of everyday life from local foods to institutions; and film, song and media references that may be unknown to an audience living in a different media arena. ${ }^{12}$ Especially with comedies and sitcoms, every joke must be adapted to the tastes and humour of the national public: the frequent use of a laugh track adds another layer of constraint, imposing not only that the jokes be translated but also that the same rhythms and timings be used as in the original. A flat pun could be seen by the audience as a sign of weakness in the comedy, thus affecting the perception of the whole series.

The adaptor works at the same time on these three often contrasting levels, trying to produce a version of the original that is accurate - if not in its individual words then at least in its meaning and tone - and to simplify the dubbing step. For instance, it is a complex combination of simplification, synchronism issues and semantic choices that forces the dialogist to change the adaptation of fake-Canadian word 'hydro-bill' from 'elettro-bolletta' ('electro-bill'), chosen by the translator, to 'elettro-prelievo' ('electro-withdrawal'), in order to make the compound word used in the first scene of a How I Met Your Mother episode (Fig. 1, 2 and 3) more funny and ridiculous for a non-English-speaking viewer.

Moreover, sometimes the changes to the original text can be considered as a form of censorship: using the Italian audience's needs as an excuse, the adaptation can weaken some aspect of the series, especially regarding sexuality, strong language, politics or religion. While it is true that these areas are crucial in the editing process, this phenomenon is more properly a form of self-censorship: without any pressure from the network, according to a sensibility developed over time, adaptors often choose to eliminate problematic elements to avoid subsequent rework. Time and budget constraints and professional habits are more powerful than any intent to erase controversial

9 Thomas Herbst, 'Why Dubbing is Impossible' and Gianni G. Galassi, 'Torna a casa lessico' [Vocabulary comes home], in Christine Heiss, Rosa Maria Bollettieri Bosinelli, eds., Traduzione multimediale per il cinema, la televisione e la scena [Multimedia translation for film, television and the stage], Clueb, 1996.

10 Luca Sandri, adaptor and dubbing director for the Italian edition of How I Met Your Mother, interview, 2010.

11 Lawrence Venuti, The Translator's Invisibility, Routledge, 1995.

12 Luca Barra, Risate in scatola, 129-183. See also Elisa Perego, Christopher Taylor, Tradurre l'audiovisivo [Audiovisual translation], Carocci, 2012. 
elements.

It must be noted, in addition, that the extent of these modifications has changed in recent decades. ${ }^{13}$ In the nineties, the push towards domestication often changed entire storylines, with Fran Drescher becoming an Italian American from the Ciociaria region in The Nanny ${ }^{14}$, or The Simpsons' characters speaking in southern regional dialects, like Neapolitan and Sardinian. ${ }^{15}$ Several years on, however, the appreciation of the cultural value of the TV series and the general Italian audience's greater comprehension of the English-speaking world has helped the adaptors in foreignizing and in maintaining the original references.

The adaptor's final task is to split the Italian script of every episode into single pages and smaller segments, called 'rings' (anelli), because the celluloid was originally cut and tied in a circular form: this mark (segnatura) will be useful during the dubbing.

At this point, the translated draft has been rewritten several times, becoming something quite different: a dialogue arranged to video for synchrony, modified in problematic passages and meanings, and divided into smaller modules. Every stage loosens the link with the original text while facilitating the most 'mechanical' and structured part of the whole mediation process: dubbing.

\section{Dubbing: An Invisible Art (and Practice)}

The next stage in the making of the Italian edition of a TV series - dubbing - entails a series of well-defined steps, where various professionals with different skills follow an intricate set of written and unwritten rules, to record the Italian voice soundtrack of every episode. Time and budget are fundamental factors, often affecting production routines and creative needs. ${ }^{16}$

First, the dubbing phase must be carefully prepared, to facilitate and accelerate the subsequent activity. On one hand, the different characters' Italian voices have to be chosen: main actors are selected through a casting process involving broadcasting executives, while minor roles are allocated more freely, taking into account similarity to the original voice, age and physical type or just the person's availability on the right days or their ability to reach the studio at short notice. On the other hand, the management prepares the working plans, carefully indicating to the professionals which 'rings' need to be dubbed, and scheduling their work into shifts. The overall job demands precise planning. The basic labour unit is the 'dubbing shift' (turno di doppiaggio), lasting three hours. Every day comprises three shifts. During a shift, the Italian dialogue lines of various episodes and episode parts are recorded, often in a non-chronological order, according to the production need to compress the number of shifts for each TV series. In most cases, the dubbers record their lines alone, in the so-called 'single column' (colonna singola) or 'separate column' (colonna separata), interacting with the other characters' original English voices: the dialogues can be less realistic, but this system guarantees more precise control over the individual recordings and helps save time and money.

Given how the work is organized, therefore, the dubbing phase has a strongly modular character. Every episode and season of a TV series is split into dialogue segments (the 'rings'), mixed and recomposed according to the requirements of every shift. The Italian version of the episode is assembled shift by shift, with the voices of each dubbing actor put together in the correct order:

\footnotetext{
13 Aldo Grasso, Storia della televisione italiana [History of Italian television], Garzanti, 2005.

14 Chiara F. Ferrari, Since When is Fran Drescher Jewish? Dubbing Stereotypes in The Nanny, The Simpsons, and The Sopranos, University of Texas Press, 2011.

15 Luca Barra, 'Springfield, Italia. Slittamenti e conversioni di senso nell'adattamento italiano di una serie televisiva statunitense' [Springfield, Italy. Shifts and changes of meaning in the Italian adaptation of an American television series], Studi culturali, 4(2), 2007, 207-231.

16 George M. Luyken, Thomas Herbst, Jo Langham-Brown, Helen Reid, Herman Spinhof, Overcoming Language Barriers in Television. Dubbing and Subtitling for the European Audience, European Institute for the Media, 1991
} 
The voice of the individual dubber is denuded of all its supporting elements. As the other voices are gradually added into the scene, everything falls into place. At first, you can only imagine what the result will be like. ${ }^{17}$

Dubbing facilities are usually composed of two spaces with different functions. In a soundproofed 'dubbing room' (sala di doppiaggio), the dubbers record their lines under the dubbing assistant's watchful eye. In the 'control room' (sala di regia), the dubbing director supervises operations, and a sound technician operates the recording machines. Between the two spaces, a glass panel reveals what is happening on screen, and microphones make communication possible when needed.

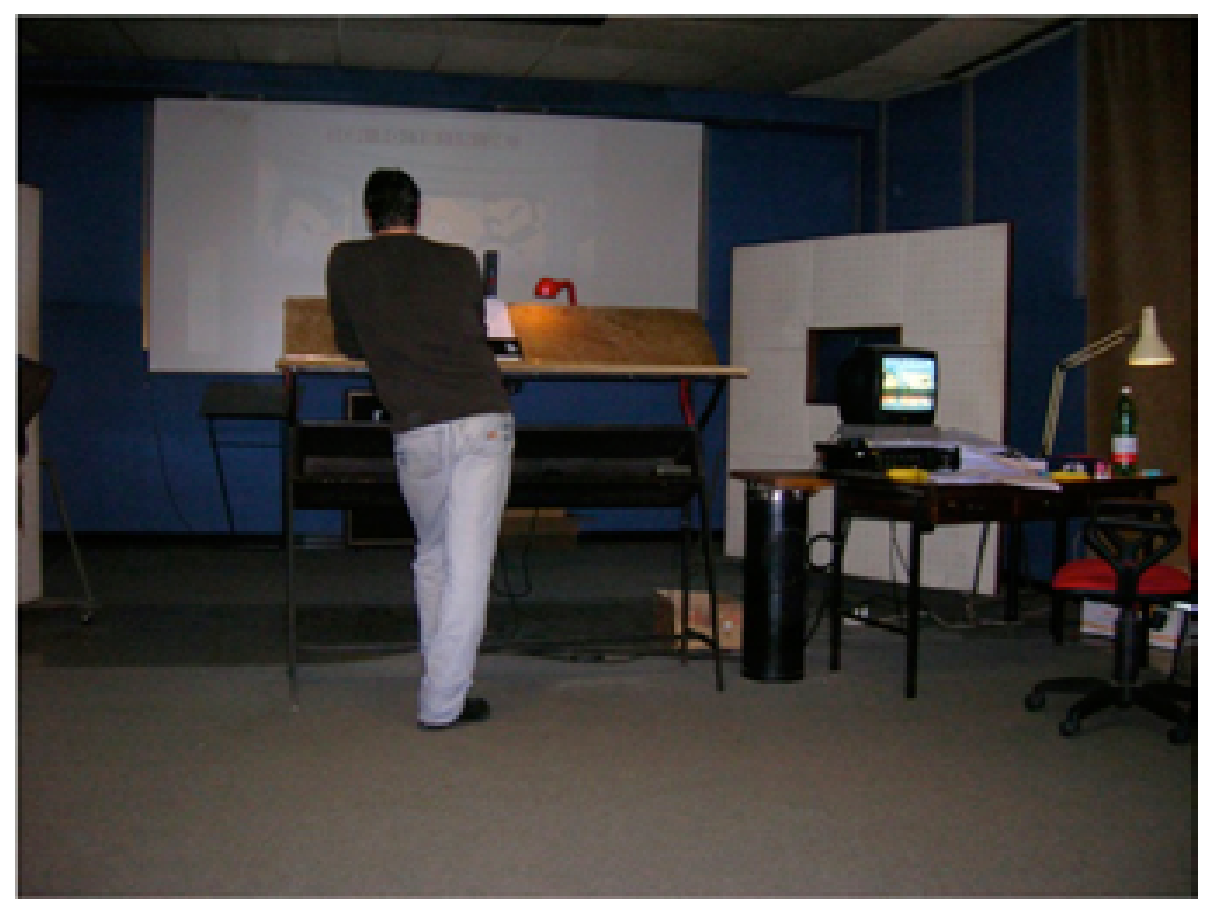

Fig. 4. The dubbing room during work on an episode of The Simpsons

The dubbers, or - as they like to call themselves - the 'halved actors' (attori dimezzati), ${ }^{18}$ act the Italian lines of a character to be recorded and combined with the video. In the dubbing room, they watch the episode video and listen through their headphones to the original voice of the foreign actors or to the Italian tracks already recorded by other dubbers. In front of them, together with the Italian adapted script with the lines that have to be acted, a red light indicates when recording is under way. Usually, dubbing actors do a first rehearsal and then record a part of a ring, or a full ring. These professionals have to re-evoke and reproduce every part of the original acting, not just the dialogue; pauses, laughs, sighs and mumbles need to be fully remade by the Italian voices, following the rhythm of what can be seen on screen. After the first recording, if deemed necessary, partial or total retakes may be made, following the dubbing director's instructions, in order to obtain the best possible outcome.

Together with the dubbing actors, a dubbing assistant is often present in the dubbing room. He/she performs a couple of technical tasks: checking the synchrony in the lines recorded by the dubbers, focusing on the length and the endpoints of every phrase; and documenting and counting the episode lines that have been recorded in every shift.

\footnotetext{
17 Interview recorded during the participant observation during the dubbing of How I Met Your Mother, 2010.

18 Alberto Castellano, ed., Il doppiaggio. Profilo, storia e analisi di un'arte negata [Dubbing. Profile, history and analysis of a hidden art], Aidac, 2000.
} 


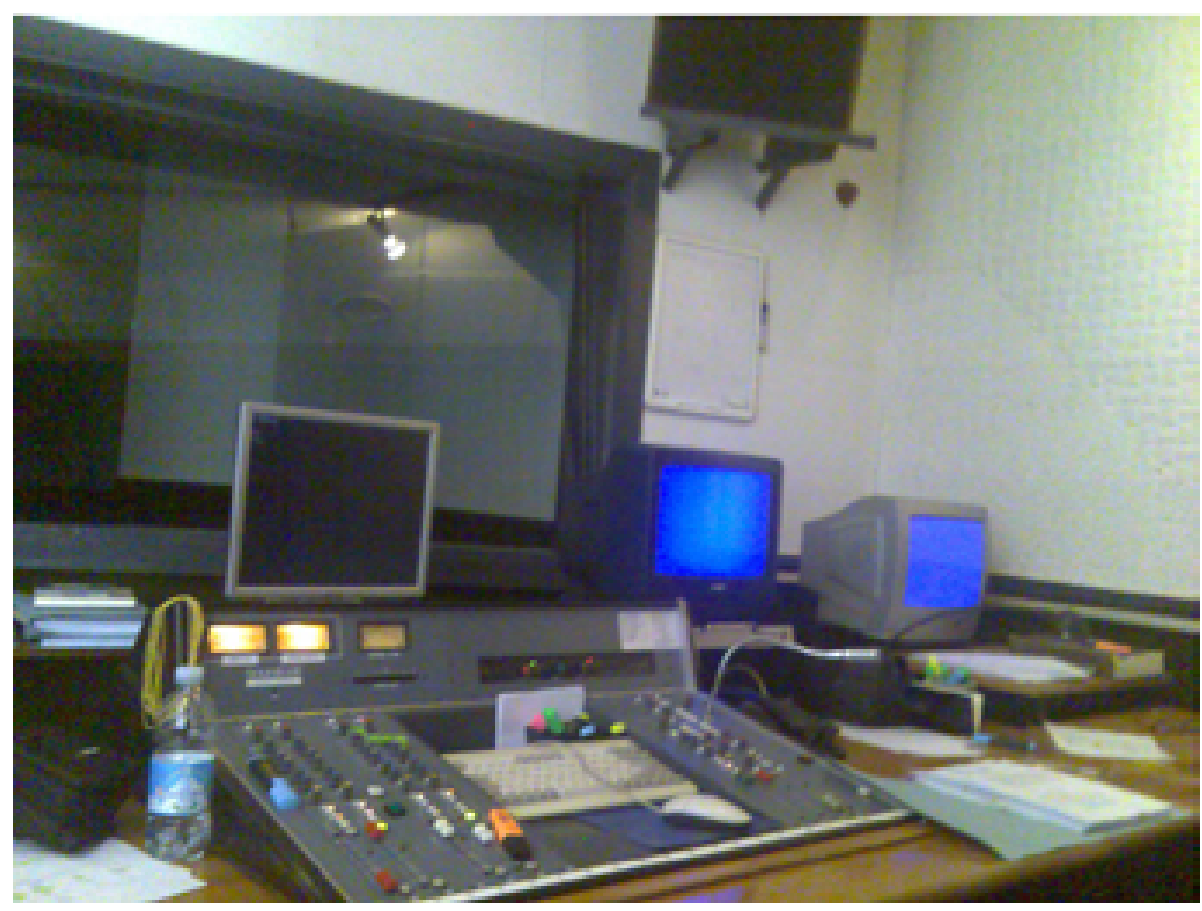

Fig. 5. The control room during work on an episode of How I Met Your Mother

Inside the control room, the dubbing director coordinates all the dubbers' work, deciding which dialogue segment must be recorded each time, establishing its beginning and end, and informing the others of the ring number and the video time code. He/she helps the voice actors, telling them the context of the lines in the episode plot, explaining the jokes included in the dialogues, and giving useful guidance on the main difficulties in the dialogue. Instructions are imparted on the times, rhythms and lengths of the phrases - 'don't run', 'make it shorter', 'let's start a second earlier' - on voice intonation and pronunciation - 'you're falling', 'it's too nasal', 'a little less messy, please' - and on more editorial and artistic aspects - 'put some irony into the line', 'you have to be cold at the beginning and sadistic at the end', 'do it like a commercial.' ${ }^{19}$ In general, the dubbing director assures the quality of the Italian edition: while the dubbers work on several projects at the same time, the director has the full picture of the title as a whole, checking the work of various professionals and ensuring that it is all up to standard. On occasion, if necessary to make the Italian dialogues sound better or to correct some recurring problem, the dubbing director may modify the script, changing some words in the dialogues. These corrections - minor modifications to synonyms, verb tenses, adjectives and other details, or more significant alterations to references, jokes and wordplay - are made on the fly, in real time, and solving one problem can lead to others.

The last professional to be involved in the dubbing phase is a specialized sound technician, who records multiple versions of all the dubbed voices, selects the best tracks, anticipates the natural delays between spoken phrases and the video, and keeps a record of the different starting points. The professional practices involved in dubbing are well defined and firmly rooted, with precise roles established over several decades and a terminology that often has its roots in the early days of film. Within the strict timescales and budgets imposed by the broadcasters - which often send a representative to the dubbing studio to make random checks on the Italian edition - the standardized process ensures that the various professional activities involved are all performed to best overall effect. There are some exceptions to this routine. For instance, when songs or musical passages have to be translated into the national language, special dubbing shifts (turni cantati) offer dubber-singers more time to work closely with the director to rehearse and record every section of the song. Other examples are the 'buzz shifts' (turni di brusio), where mass 
scenes and minor characters with just one line are dubbed all together, as various dubbing actors rapidly record individual and collective roles (e.g. a group of children). During other actors' shifts, 'remakes' (rifacimenti) can still be made: if the director is not satisfied with the previous recording of a piece of dialogue, he/she can recall the actor for another take, which can be done in a few minutes when director and dubber are both available.

After every single line of the season has been recorded, post-production can start. First, the audio tracks of the Italian version are put together and synchronized with the video; then, these are mixed with the fixed parts of the international soundtrack (background noises, music, canned laughter for sitcoms, etc.) to obtain the complete Italian soundtrack. Alongside this process, some changes are made on video too, in an editing process that adds subtitles, explanations and other graphics for elements that need adapting to the Italian dialogues and the needs of the national audience. After the (dubbed) audio and the (slightly modified) video have been matched, the Italian edition of every episode is now complete and ready to be broadcast in a carefully selected slot to reach the widest possible audience.

As is now clear, during the dubbing phase, carefully adapting original texts and ensuring the artistic quality of the work are just two of the main concerns. Although essential parts of any project, these tasks are adapted to suit different goals and work habits. The balance between the fixed, stable presence of the dubbing director, who oversees the series in its entirety, and the fleeting presence of the dubbing actors, who often have to switch between completely different characters in the space of just a few hours, is also an important factor. So is the modularity of the process, as every scene is sliced into many pieces that will be reconstructed only at the end. The financial and time constraints and the various alterations to the adapted text also contribute to an incremental construction of the Italian dialogue under several professionals' control, as it departs further and further from the plain translation of the original text.

\section{To Be Continued... The Seriality Issue}

As the above reconstruction of the 'mediation' processes that build the Italian edition of a foreign TV series clearly shows, besides editorial attention to the correct translation and adaptation of the original texts, several changes and modifications are made under standard working practices and habits to simplify the work or to reduce lead times and costs. The role of the 'invisible mediators' - the professionals who contribute their varied expertise, working to different goals, to build the incremental national dialogue piece by piece - must not be underestimated. Indeed, knowledge of their established ideas, professional practices and traditions helps us understand the wide range of alterations made to every foreign TV episode, thus affecting how it may be received by Italian audiences.

In addition, the serial nature of TV programmes, grouped as they often are into seasons and episodes, cuts across the modularity of the work routines in other ways, adding another layer of complexity. To dub a single season takes several weeks; a year later, all the dubbers and other professionals usually come together again to work on the subsequent season: in the meantime, they have contributed to several other movies and TV series. The Italian edition of a series forms part of multiple workflows, leading to possible continuity issues: since the professionals rarely look to previous years' translation and adaptation choices, sometimes the same joke can appear in different ways in the national version; voices and intonations may slightly change; recurrent catchphrases are not correctly identified, and so on. Exacerbated by the lack of reference to the previous adaptations, the Italian mediators' job is, in some ways, 'blind': unlike the original authors, dubbing professionals have no idea about how the characters are going to develop, e.g. a minor character (whose voice may have been chosen without much thought) may acquire a major role, thus leading to poor results or drastic changes. Moreover, the Italian edition must take into account the Italian editions of other media, too. Thus, the same voice can be used for the same actor in different contexts, and references incomprehensible to the audience can be avoided: in How I Met Your Mother, 'Woooo!', 4: 8, for example, the reference to Mad Men was replaced with No Country for Old Man, also because the Mad Men series had not been broadcast yet in Italy. The consequences of seriality and a complex media system thus bring other 'distortions' to the Italianized versions of TV shows. 
Lastly, it is important to underline how the creation of the Italian edition of TV series is an intermediate phase in between other important moments that can influence and affect how foreign texts are received domestically and can profoundly change not only their dialogues but also their meanings and values. Before adaptation and dubbing, international markets, acquisitions and licence contracts ${ }^{20}$ set the rules for what broadcasters can do with the series, establishing a licence period and a number of runs (and reruns). After that, scheduling choices (selecting a network and time slot, organizing blocks, strips and marathons, adopting a repetition pattern $)^{21}$ and promotion, on air and across other media (print, online, etc.), ${ }^{22}$ construct and give meaning to the relationship between the text and the viewers. Italian editions must be seen in the wider context of a large production chain.

In conclusion, as this paper has shown, the work of the adaptation and dubbing professionals, which is often taken for granted, concretely shapes the different product that Italian audiences will encounter, and their practices, working constraints and traditional routines are fundamental for a more developed comprehension of the real dynamics involved in the global circulation of media contents and products.

\section{B i o graph y}

Luca Barra, PhD, is Research Fellow at Università Cattolica del Sacro Cuore, in Milan, where he teaches Media Economics and TV Scheduling. He is senior researcher at Ce.R.T.A. - Centro di Ricerca sulla Televisione e gli Audiovisivi. His research focuses on the international circulation of media products, the history of Italian TV, and the evolution of the contemporary media landscape. He has published a book - Risate in scatola (Vita e Pensiero, Milan 2012) - and several essays in edited books and journals, and he contributes regularly to the Italian television studies journal Link. Idee per la televisione.

20 Denise D. Bielby, Christina L. Harrington, Global TV. Exporting Television and Culture in the World Market, New York University Press, 2008.

21 The important role of selecting programs and inserting them in a specific timeslot is highlighted by John Ellis, 'Scheduling. The Last Creative Act in Television?', Media, Culture \& Society, 22(1), 25-38, 2000.

${ }^{22}$ Networks can add value to their programming adopting strategies of program and network branding. See Catherine Johnson, Branding

Television, Routledge, 2012. 